\title{
Introduction of home exercise program for current circumstance worldwide
}

\begin{abstract}
Due to current pandemic of Coronavirus disease-2019 (COVID-19), elderly people tend to show deterioration of physical and cognitive function and exacerbation of nutritional status, leading to the progression of sarcopenia and frailty. Recent topic includes the National Center for Geriatrics and Gerontology-Home Exercise Program for Older People (NCGG-HEPOP) 2020. It has six packs for health maintenance, such as balance improvement, strengthening, inactivity prevention, feeding/swallowing improvement, nutrition improvement and cognition. The pandemic may bring decreased social interaction, decreased physical activity, and increased physical stress of viral infection. NCGG-HEPOP will hopefully prevent such exacerbation in the light of geriatrics and rehabilitation medicine.
\end{abstract}

Keywords: frailty, physical activity, rehabilitation, exercise, vaccines, Coronavirus disease-2019

\author{
Volume I4 Issue 4 - 202I \\ Hiroshi Bando, ${ }^{1,2}$ Mitsuru Murakami, ${ }^{3}$ Akito \\ Moriyasu 4,5 \\ 'Tokushima University/Medical Research, Japan \\ Japan Masters Athletics, Tokushima division, board, Japan \\ ${ }_{3}^{3}$ Japan Masters Athletics, Kagawa division, vice-president, Japan \\ ${ }^{4}$ Rehabilitation Research Group for body and heart in Shikoku, \\ Japan \\ ${ }^{5}$ Akiboshi Bright Star training rehabilitation center, Japan
}

Correspondence: Hiroshi BANDO, Tokushima University / Medical Research, Nakashowa I-6I, Tokushima 770-0943 Japan, Tel +8I-90-3 I87-2485, Email pianomed@bronze.ocn.ne.jp

Received: August 16,202I| Published: August 27, 2021
Abbreviations: NCGG, national center for geriatrics and gerontology; HEPOP, home exercise program for older people; COVID-19, coronavirus disease-2019

\section{Commentary}

Currently, the pandemic of Coronavirus disease-2019 (COVID-19) has been crucial problem worldwide. ${ }^{1}$ Lots of people are restricted in their behavior. ${ }^{2}$ In particular, elderly people are at high risk of becoming serious due to COVID-19 infection. ${ }^{3}$ Then, physical activity and social interaction have also decreased. ${ }^{4}$ For the elderly, deterioration of physical and cognitive function as well as exacerbation of nutritional status are observed. Consequently, there are concerns about the progression of sarcopenia and frailty. ${ }^{5}$

In such social situation, the balance between infection prevention and activity maintenance would be important. For healthy life expectancy, specific tools have been recently developed. ${ }^{6}$ This is the National Center for Geriatrics and Gerontology-Home Exercise Program for Older People (NCGG-HEPOP) 2020. ${ }^{7}$ This paper introduces this program and related matters.

How much exercise and activity were actually reduced by COVID-19? There are data for 30days after the WHO pandemic declaration. The average steps in 455 million subjects in 187 countries decreased by 1432 steps $(27.3 \%) .{ }^{8}$ An internet survey of 2381 patients aged $\geq 18$ years reported reduced physical activity in $43 \%$ of subjects. ${ }^{9}$ Another study uses wearable devices to track individual physical activity levels. The average steps for 30million users were 7\% -38\% lower in mid-March 2020 compared to the same period last year in almost all countries. An internet survey of 1600 elderly people aged $\geq 65$ showed that physical activity time per week decreased by about $30 \%$ (about 60 minutes) after the pandemic. ${ }^{10}$ Furthermore, during the emergency period for 40days from April, the steps decreased by up to $30 \% .{ }^{11}$ During this period, $41 \%$ of outpatients refrained from visiting the hospital for dementia rehabilitation at NCGG facilities.

Research on the influence of COVID-19 on various subjects has progressed in many fields. As a result, subjects who originally had some underlying diseases were more likely to become seriously ill. ${ }^{12}$ Further, older people were much more likely to become severe compared to younger people. Among these, fatality rate was increased dramatically with advancing age. The occurrence of numerous clusters and frequent deaths of the elderly has been found in the hospitals, long-term care facilities, community gatherings and so on. ${ }^{13,14}$ In addition, significant news has spread around the world. They include the infection and sudden death of older people who have been active in their daily lives, the lockdown in many cities, the collapse of medical care, and the interrupt of artificial respirators for the elderly. It means the situation for clinical triage procedure of the elderly. ${ }^{11}$

This situation involves major problems. For many years, sincere research and practice on ageism has been carried out. Among them, optimal medical care and care has been provided for extending healthy longevity, maintaining daily activities, and improving QOL. However, it is the astonishing fact that such triage has to be used owing to COVID-19 infection. ${ }^{15}$ In other words, it showed the impact of overturning the medical ethics that underlie geriatrics and rehabilitation medicine.

The COVID-19 pandemic cause's indirect stress such as inactivity, decreased social interaction, and decreased physical activity, as well as the direct physical stress of viral infection. There is no doubt that this continuation will exacerbate the frailty. Adequate method to manage both of them would be important ${ }^{16}$ and concrete measure has been tried as NCGG-HEPOP.

NCGG-HEPOP can be judged by applying a flowchart as to the situation of the elderly. ${ }^{6,7}$ Among them, there are three main items related to exercise: i) balance improvement pack, ii) strengthening pack, and iii) inactivity prevention pack. In addition, there are two types of iv) feeding and swallowing improvement packs and v) nutrition improvement packs related to swallowing/oral frailty, and vi) cogni-pack related to cognitive frailty. In this way, these six packs can cover elderly problems (Figure 1). The benefits of HEPOP include i) easily clarifying mental and physical problems with a flowchart, ii) including 6 kinds of various aspects and concepts, and iii) selecting and quickly conducting an appropriate exercise. 


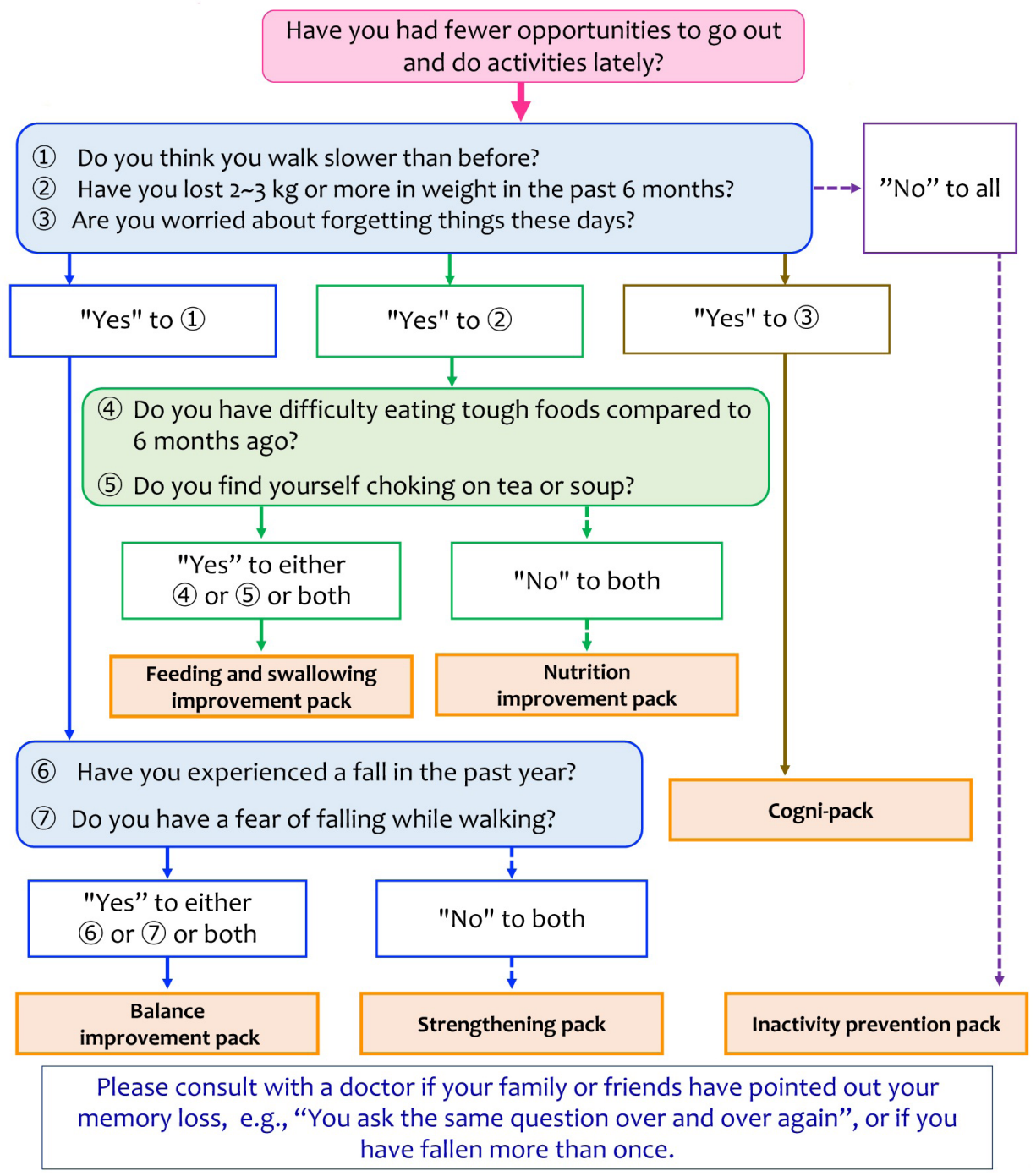

Figure I NCGG-HEPOP 2020 stands for National Center for Geriatrics and Gerontology-Home Exercise Program for Older People (NCGG-HEPOP) 2020 It has 6 packs useful for health maintenance.

In the light of sports medicine, exercise choices are effective for frail and sarcopenic elderly. ${ }^{17,18}$ When aiming for muscle strengthening by resistance exercise, it is certainly ideal to carry out a high load of $70-80 \%$ of a repetition maximum (1RM). However, recent studies on elderly people have reported that muscle strengthening can be obtained even with a low output of about $20 \%$ of $1 \mathrm{RM},{ }^{19}$ and that even about $16 \%$ can promote muscle protein synthesis. ${ }^{20}$ Prevention of dysphagia is also important for the prevention of frailty and sarcopenia. ${ }^{21,22}$ In this way, the entire cover of HEPOP would be expected.

Finally, for COVID-19, the development of vaccines and therapeutic agents has been in progress for pandemic COVID-19. However, short-term improvement is not easy. The crucial point would be adequate balancing of some measures of stability and activity. ${ }^{23}$ For the period of with and/or post COVID-19 era from now on, the elderly will manage problems of reduced mental and physical reserves and resilience from stress. ${ }^{24}$ Home exercise program will hopefully become a useful tool for obtaining resilience to various changes.

\section{Acknowledgments}

None.

\section{Conflicts of interest}

Author declares there are no conflicts of interest.

\section{Funding}

None.

\section{References}

1. Bando H. Latest Data of COVID-19 Influencing Worldwide From John Hopkins University. Int J Case Rep Clin Image. 2021;3(3):157.

2. Després JP. Severe COVID-19 outcomes - the role of physical activity. Nat Rev Endocrinol. 2021;17(8):451-452.

3. Ito K, Piantham C, Nishiura H. Predicted dominance of variant Delta of SARS-CoV-2 before Tokyo Olympic Games, Japan, July 2021.Euro Surveill. 2021;26(27):2100570.

4. Bando H. Recommended adequate exercise for diabetic patients in response to new lifestyle manner with corona era for Global health. MOJ Public Health. 2020;9(4):113-115.

5. Murakami M, Moriyasu A, Bando H. Better Application of Exercise Prescription with Adequate Supports to All People. Biomed Sci J. 2020;1:04. 
6. Kawamura K, Kamiya M, Suzumura S, et al. Impact of the Coronavirus Disease 2019 Outbreak on Activity and Exercise Levels among Older Patients. Nutr Health Aging. 2021;25(7):921-925

7. National Center for geriatrics and Gerontology (NCGG), Tokyo, Japan Home Exercise Program for Older People (HEPOP) 2020.

8. Tison GH, Avram R, Kuhar P, et al. Worldwide Effect of COVID-19 on Physical Activity: A Descriptive Study. Ann Intern Med. 2020;173(9):767770.

9. Górnicka M, Drywień ME, Zielinska MA, et al. Dietary and Lifestyle Changes During COVID-19 and the Subsequent Lockdowns among Polish Adults: A Cross-Sectional Online Survey Life COVID-19 Study. Nutrients. 2020;12(8):2324.

10. Yamada M, Kimura Y, Ishiyama D, et al. Effect of the COVID-19 Epidemic on Physical Activity in Community-Dwelling Older Adults in Japan: A Cross-Sectional Online Survey. J Nutr Health Aging. 2020;24(9):948-950.

11. Rosenbaum L. Facing Covid-19 in Italy - Ethics, Logistics, and Therapeutics on the Epidemic's Front Line. $N$ Engl J Med. 2020;382(20):1873-1875.

12. Goyal P, Choi JJ, Pinheiro LC, et al. Clinical Characteristics of Covid-19 in New York City. N Engl J Med. 2020;382(24):2372-2374.

13. Ruan S. Likelihood of survival of coronavirus disease 2019. Lancet Infect Dis. 2020;20(6):630-631.

14. Onder G, Rezza G, Brusaferro S. Case-Fatality Rate and Characteristics of Patients Dying in Relation to COVID-19 in Italy. JAMA. 2020;323(18):1775-1776.

15. Kuylen MNI, Kim SY, Ruck Keene A, et al. Should age matter in COVID-19 triage? A deliberative study. J Med Ethics. 2021;47:291-295.
16. Lim WS, Liang CK, Assantachai P, et al. COVID-19 and older people in Asia: Asian Working Group for Sarcopenia calls to actions. Geriatr Gerontol Int. 2020;20(6):547-558.

17. Dent E, Lien C, Lim WS, et al. The Asia-Pacific Clinical Practice Guidelines for the Management of Frailty. $\mathrm{J} \mathrm{Am} \mathrm{Med} \mathrm{Dir} \mathrm{Assoc.}$ 2017;18(7):564-575.

18. Arai H, Wakabayashi H, Yoshimura Y, et al. Chapter 4 Treatment of sarcopenia. Geriatr Gerontol Int. 2018;18Suppl 1:28-44.

19. Van Roie E, Delecluse C, Coudyzer W, et al. Strength training at high versus low external resistance in older adults: effects on muscle volume muscle strength, and force-velocity characteristics. Exp Gerontol. 2013;48(11):1351-1361.

20. Agergaard J, Bülow J, Jensen JK, et al. Light-load resistance exercise increases muscle protein synthesis and hypertrophy signaling in elderly men. Am J Physiol Endocrinol Metab. 2017;312(4):E326-E338.

21. Wirth R, Dziewas R, Beck AM, et al. Oropharyngeal dysphagia in older persons - from pathophysiology to adequate intervention: a review and summary of an international expert meeting. Clin Interv Aging. 2016;11:189-208

22. Moriyasu A, Murakami M, Bando H. Rehabilitation nutrition care for elderly people with sarcopenia and nutritional disorders. Int J Complement Alt Med. 2020;13(3):121-123.

23. Osawa A, Maeshima S, Kondo I, et al. Balancing infection control and frailty prevention during and after the COVID-19 pandemic: Introduction of the National Center for Geriatrics and Gerontology Home Exercise Program for Older People Home Exercise Program for Older People 2020. Geriatr Gerontol Int. 2020;20(9):846-848.

24. Bando H. The influence of physical activity and sedentary behaviors on severity of COVID-19 in the clinical practice. SunText Rev Virol. 2021;2(1):118. 